\title{
Medical Ethics: Lessons Learnt from the Past and the Way Forward for the Future Based on Milgram ${ }^{\text {ee }}$ And Zimbardo"s Work and Its Ethical Implications in the Contemporary Society
}

\author{
Dodampahala S. H. ${ }^{1}$, Dodampahala S. K. ${ }^{2}$, Rahubaddha A. N. ${ }^{3}$ \\ ${ }^{1}$ Associate Professor, Department of Obstetrics and Gynecology, Faculty of Medicine, University of Colombo, Sri Lanka \\ ${ }^{2}$ Undergraduate Research Student \\ ${ }^{3}$ Research Associate, Department of Obstetrics and Gynecology, Faculty of Medicine, University of Colombo, Sri Lanka
}

\begin{abstract}
The two separate studies conducted by the renowned psychologists Stanley Milgram and Philip Zimbardo were both aimed at understanding human behavior in social situations. Results of these studies are compatible with each other and share a common conclusion that the Individual behavior is largely under the control of social forces and environmental contingencies rather than personality traits (1), (4). These studies also share the notoriety of being two of the most controversial studies carried out on human subjects that have grossly violated the ethics that govern the modern day research.
\end{abstract}

Keywords: Milgram, Zimbardo, medical ethics, ethics in Reproduction

\section{Milgram's Experiment}

Stanley Milgram, a psychologist at Yale University,in 1961, conducted an experiment focusing on the conflict between obedience to authority and personal conscienceafter the infamous Nuremberg War Criminal trials. Through his studies he wanted to analyze how easily ordinary people could be influenced into committing atrocities because they had to be obedient to an authority figure.

In this particular study, volunteers were recruited for a lab experiment supposedly investigating "learning". The volunteer, who was assigned the duty of ,teacher", was introduced to a third participant, the ,learner"e who was actually a confederate of the investigator. The learner was strapped to a chair with electrodes. After he had learned a list of word pairs given him to learn, the teacher had to test him by naming a word and asking the learner to recall its pair, failing which the teacher was told to administer an electric shock. The level of shock, ranging from 15 to 450 volts, was increased every time a wrong answer was given. When the teacher refused to administer a shock the experimenter gave a series of orders to ensure that they continued.

After a series of experiments, Milgram concluded that an ordinary person was likely to follow orders given by an authority figure, even to the extent of gravely hurting and killing an innocent human being. He summed up the findings in the article ,The Perils of Obedience ${ }^{\text {ee }}$ writing "The extreme willingness of adults to go to almost any lengths on the command of an authority constitutes the chief finding of the study and the fact most urgently demanding explanation" (2),(3).

\section{Zimbardo's Experiment}

Professor Philip Zimbardo, in 1973, conducted an experiment at the Stanford University, hence widely known as the „Stanford Prison Experiment ${ }^{\text {e }}$, to determine whether our behavior was more situational or dispositional. Participants were randomly assigned to either the role of prisoner or guard in a simulated prison environment in a basement of the Stanford University. Zimbardo observed the behavior of the prisoners and guards acting as the prison warden.

Within a very short time of inception of the study, both guards and prisoners were settling into their new roles. Some of the guards started harassing the prisoners in a sadistic manner and were joined by the other guards in unison. The prisoners soon adoptedprisoner-like behavior as well becoming submissive and dependent on the guards. They had distanced themselves from the reality and were deeply engulfed in their roles by the second day of the study that they started a rebellion. The guards duly retaliated by using a fire extinguisher to blow cold carbon dioxide at the rebels followed by a strip search. The ringleaders of the prisoner rebellion were placed into solitary confinement. After this the guards began to harass and intimidate the prisoners more freely.

Zimbardo had initially intended that the experiment should run for two weeks, but on the sixth day it was terminated after one of his students pointed out the inhuman treatment received by the prisoners. Until this point, Zimbardo, being the prison warden, had not realized the fate of the inmates as he was also deeply engaged in role playing. His own account describes that, "It wasn't until much later that I realized how far into my prison role I was at that point -that I was thinking like a prison superintendent rather than a research psychologist". 


\section{International Journal of Science and Research (IJSR) \\ ISSN (Online): 2319-7064 \\ Index Copernicus Value (2013): 6.14 | Impact Factor (2014): 5.611}

Before the research concluded, one participant had bouts of uncontrollable screaming, crying and anger. His thinking had become disorganized and appeared to have been entering the early stages of a deep depressionwithin 36 hours of initiation of the study.Within the next few days three others also had to be released after showing signs of emotional distress and early depression. (5),(6), (7).

\section{Contemporary Ethics Concerning Human Studies}

Subsequent to the much publicized „Nuremberg Trials ${ }^{\mathrm{ee}}$, it was agreed upon, that human research should be carried out adhering to ethics and principles. Ten such principles were brought forward at the Counsel of War Crimes in Nuremberg in 1947. These principles constituted the „Nuremberg Code"e, which although was not directly incorporated in to the law, is the first accepted code of conduct concerning the ethical aspects of human research (8). These principles were later included in the „Declaration of Geneva ${ }^{e e}$, which was regarded as a statement of physicians' ethical duties. In 1964, „Declaration of Helsinkiee was put forward by the World Medical Association (9). It is widely regarded as the cornerstone of human research and has since undergone seven revisions in order to keep up with the modern trends of research. These ethics are the basis for the „Code of Federal Regulations ${ }^{\text {ee }}$ of which part 46, ,Protection of Human Subjects ${ }^{e e}$, under title 45, ,Public Welfare ${ }^{e e}$, governs the research ethics in the United States(10).

Ethical Issues Concerning Milgram's Experiment and Its Relevance to Present-day Ethics

Deception was used as a tool in Milgram es study that the participants were fraudulently led to believe that they were shocking a real person, and were unaware the learner was a confederate of Milgram's. The participants were also kept in the dark regarding the motive of the study as well. They were only told the study was about "learning". In this situation Milgram had deprived the participants of informed consent and by doing so, their right to information.During the study, participants were exposed to extremely stressful situations that could have had the potential to cause psychological harm. According to Milgram 's own observations many of the participants were visibly distressed.The principle that "the experiment should be set up in a way that avoids unnecessary physical and mental suffering and injuries" was breached in this regard.,Right to withdrawale ${ }^{\text {ee }}$ was also looked over by Milgram. He did not provide an opportunity to the participants to withdraw at their will as he discouraged them by producing verbal prods.

These aforementioned instances show that Milgram has violated several ethics concerning human studies specially by not obtaining proper informed consent and also by bringing a lot of distress and suffering to the subjects. These instances would have garnered him serious legal implications had it happened in the present day. The ethics review committee (or IRB), to which the research proposal has to be submitted beforehand, would have duly not given Milgram ethical clearance to carry out the study. Hence in the present day this study would not have been a possibility.

\section{Ethical Issues Concerning Zimbardo's Experiment and Its Relevance to Present-day Ethics}

In the Stanford prison experiment, Zimbardo violated the ethics concerning the fully informed consent as he himself was not aware of the outcome of the study. Additionally the participants had not submitted consent to being arrested by the police which they did to bring in a more realistic sense in to the study. Also, participants playing the role of prisoners were exposed to psychological and physical harm, experiencing incidents of humiliation and distress. This, as in the case of Milgram "s, has grossly violated the ethics regarding prevention of unnecessary mental and physical harm to the subjects. If Zimbardo carried out this particular study in modern day, it could have brought him extensive legal problems. Furthermore he could have not conducted this study as it would be duly rejected or heavily moderated, if approved by any chance, by an ethics review committee (or an IRB).

\section{Conclusion on Alleged Ethical Violations Committed by Milgram and Zimbardo}

Milgram and Zimbardo, although since been challenged by many psychologists on the authenticity of the findings and accuracy of the methodology, carried out two infamous studies to understand the relationship between human behavior and personal traits and environmental factors. Despite gaining important knowledge from them, these studies have garnered notoriety for the methodology according to which they were conducted, that breached many ethics pertaining to human studies. These studies if conducted today, would have been nipped in the bud by the ethics review committee (or IRB) as they grossly violate ethics and principles that govern human research. They are important events of history of human research, although to a lesser degree than ,Nuremberg Trials ${ }^{\text {ee }}$, that have opened our eyes to violation of ethics and basic human rights in the name of science. They would undoubtedly help us not only to understand the human behavior but also to protect our own kind from hazards of human studies.

\section{Contemporary Issues in Medical Ethics}

The issues faced in the medical field are quite serious and bizarre. Its spectrum ranges from genetics to fertility and reproduction, embryo transfer, selective fetocide, termination of pregnancy, newborn and paediatric ethics. Another group of doctors specialized in ethics will have to deal with physician reviews, surgery, consent for treatment, euthanasia, brain death and organ transplant. A new knowledge generation based on scientific research will require another set of research ethics that is widely dealt at ethic review committees. The ethics concerning disability and decision making capacity touch on the ethics of deciding someone"s capacity to make decisions. Long term care ethical issues exclusively deal with the issues in a patient receiving long term care. The moon is not far 
away for a physician who focuses on health reform issues which are currently under debate.

It is so amazing to see how medical ethics have evolved over a period of few decades having taken example of two well-known psychological studies and sphering the current trends of medical ethics.

\section{Conclusion}

The ethics of research have evolved over a period to provide the ultimate care of unwell. It's noteworthy that the culture and religion of an individual plays an integral part in medical ethics. There are many religions that do not allow termination or withdrawal of life support. One has to abide by the social and cultural issues and the existing laws of the land in drafting medical ethics. Therefore medical ethics don't have to be necessarily equal for each and every country.

\section{References}

[1] Milgram, S. (1963). Behavioral study of obedience. Journal of Abnormal and Social Psychology, 67, 371378.

[2] Milgram, S. (1974). Obedience to authority: An experimental view. Harpercollins.

[3] McLeod, S. A. (2007). The Milgram Experiment. Retrieved from www.simplypsychology.org/milgram.html

[4] Haney, C., Banks, W. C., \& Zimbardo, P. G. (1973). A study of prisoners and guards in a simulated prison. Naval Research Review, 30, 4-17

[5] Smith, J. R. \& Haslam, S. A. (Eds.) (2012). Social Psychology: Revisiting the Classic Studies. Sage

[6] Carnahan, Thomas; Sam McFarland (2007). "Revisiting the Stanford prison experiment: could participant self-selection have led to the cruelty?". Personality and Social Psychology Bulletin 33 (5): 603-14

[7] McLeod, S. A. (2016). Zimbardo - Stanford Prison Experiment. Retrieved from www.simplypsychology.org/zimbardo.html

[8] Annas, George J., and Michael A. Grodin. The Nazi Doctors and the Nuremberg Code. New York, NY: Oxford University Press Inc., 1992.

[9] World Medical Association (2013). "Declaration of Helsinki: Ethical Principles for Medical Research Involving Human Subjects". JAMA 310 (20): 21912194.

[10] Code of Federal Regulations | HHS.gov. 2016. Code of Federal Regulations | HHS.gov. [ONLINE] Available at: http:/www.hhs.gov/ohrp/humansubjects/guidance/45c fr46.html. [Accessed 24 March 2016] 